\title{
Perception of Partnership between Professionals and Parents of Children with Disability in Albania
}

\author{
Arbana Zhapaj \\ University "Ismail Qemali" Vlorë \\ Email: arbanam2000@yahoo.com
}

\section{Doi:10.5901/mjss.2014.v5n27p1451}

\section{Abstract}

Professionals working on children with special needs usually face difficulties on their activity. One of these difficulties consists on lack of communication and especially cooperation with the parents of the children. Parents usually experience deep anxiety during the time of following the educative and therapeutic treatment of their children, which for many of them becomes an endless marathon. But how do professionals view this relation? By the means of research professionals try to understand their relation with parents comparing it with what the latter report. Starting with how parents feel, what do they expect from their children, what are their expectations for the future, what's the family impact, and what do they expect from the professional. Through this overview professionals can conduct an auto-analysis of their perceptions, which can make them reflect on their attitudes, and lead to creation of bridges of cooperation among these actors.

\section{Introduction}

Studies show that this partnership is hard to built. In a review about the issue, Lipsky (1989) considers it a grim situation. The author argues the importance of parents' participation, and education and treating of the so-called "handicap" children.

Prejudice regarding parents' actions might be an obstacle (Donnellan et Miranda, 1984 ; Vincent, Laten, Salisbury, Brown et Baumgart, 1981). On the other hand, some parents might not see the necessity of cooperating with therapists, education institutions, or just not be able to create such a relation (Lipsky, 1989).

From the educative and therapeutic team point of view, Falvey dhe Haney (1989) suggest that the first step to achieve a good cooperation with families is found in the auto-analysis of perceptions and attitudes towards the parents, in order to create a good professional-family relation (Falvey et Haney, 1989, pp.17-19).

\subsection{We can identify different types of professionals ( J.M. Bouchard)}

The Expert-Professional. This type of professional is very concentrated on objectivity, assessment and qualitative research.

They are always updated with scientific knowledge; objectively utilize the tools; give guidance to the parents. They tend to impose their decisions based on their expertise and their accumulated professional and scientific insights.

Their knowledge becomes more hermetic given the conditions of doubtful and stubborn parents. They aim at professional values. They risk dependency to the parents, a feeling of incompetence and lack of confidence on their resources.

Leader-Professional.

They are active listeners and empathetic regarding parents. They support the idea that parents have the necessary resources to self-administer the development of themselves and their family.

This type of professional uses reflection techniques and reformulation to help the parents on their efforts

They emphasize on the individual; his subjectivity and his emotions. On their point of view, the objective of the intervention should be the integral development of the individual, parents and other members of the family.

They propose solutions and approve others' interventions. They suggest different methods while accepting the fact that parents are able to choose what's most appropriate for them. The aim of their reaction is to help parents empathize with the dynamics of their profession.

Partner-Professional 
This type of professional searches for the best solutions and shares his educative and children's development responsibility. They vulgarize their knowledge with the aim of achieving an educative role on parents (pedagogical function of profession exercise). Practical insights of the parents become a necessary means through which professional better understand the realities, needs, and resources of the families. They value the parents' principles of reciprocity and self-determination. They unite the parents and other members of the surrounding environment in order to create new social practices and individual or collective assistance for groups in need. They integrate the practical insights of each and everyone in order to create a network of learning silently.

\subsection{Professional Competences}

Good professionals should be able to utilize these 3 models in their interventions. They should adapt them depending on the context and the situation. They should respect parents' values and expectations. They should be able to vulgarize their knowledge and their practical insights. It is important that they value the parents' knowledge and resources creating an environment of knowledge exchange among parents. They should teach them to make decisions and to share them; practice adaptation and determination.

\subsection{Justice, The Power Of Application Of These Models}

These three models have their advantages and disadvantages. In these three models is marked the educative competence of the parents; their power is imposed, they are regarded as leaders or partners in self-administration. For example, parents who only use/don't use educative behavior of a single model, usually face more difficulties on the education of their children. Familiar education is considered as a means by which parents are helped to change, and grow their educative strategies inspired by the educative behavior of any of these models. The aim of educative intervention to the families should be the growth of the educative strategy varieties, which would make parents reliable on way they operate.

Many authors don't agree with the idea that parents should delegate such important matters as education of their children to the professionals. Parents, as well as interventionists, don't have other choice but to communicate and to work together for the good of the family (Mc Bride, 199?).

Parents and professionals have the same fears. They fear that they are perceived as non incompetent. They cannot know how their words are interpreted, and they rarely know what others think.

\section{Methodology}

\subsection{Participants}

Participants in the study are professionals who work with the families of disable children $(n=40)$. Participants expressed their opinion in the questionnaires, which were administered by the scholar. The involvement of field diversity of professionals was treated with special care. The geographic spread of the questionnaires involved the cities of Vlora, Fier and Tirana. Participants were randomly selected in cooperation with communitarian centers of services and special schools in the relevant regions.

\subsection{Instruments and Materials}

Questionnaires were the instruments used to gather information. The questionnaire that was completed by the professionals who work with disable persons contained a section for demographic data, 11 closed questions, where participants could choose the most appropriate alternative for their state. In the end, they were asked an open question in order to express their opinions regarding the possible interventions to improve the state of the field.

\subsection{Procedure}

The period of data gathering is May - September 2014. 


\subsection{Statistical Analysis}

The data gathered through quantitative questionnaires were coded and then statistically processed. Since the greatest parts of the variables were nominal and ordinal, percentages and frequency were analyzed. Qualitative methods of analysis were used to analyze the gathered data from the open questions

\subsection{The ethics of study conduction}

All the subjects of the study participated with their free will. They were stated that the participation in the study was grounded on volunteer contribution. In the head of each questionnaire, the methodology creator gave instructors on the purpose of the study and the way the questionnaire should be filled. During the conduction phase principles of anonymity and confidentiality were fully respected.

\section{Data Analysis and Discussion}

The purpose of the study was to draw conclusions regarding professional's perceptions on disable persons' families they work with. Treatment of special needs children is a new field in Albania and is accompanied with difficulties in creating the necessary cooperative tradition between parents and professionals. Prejudices often become the main obstacles of this relation.

The sample contains 40 professionals working in the field of disability treatment. The study is based on the questionnaires' completion. Its aim is to point out the perceptions of professionals working with special needs children, as well as their parents in the light of partnership creation, boosting credibility, and their expectations on their children's achievement.

The data are:

There are interviewed 40 professionals in several expertise fields, such as social, health, educative, administrative and judicial realms. They are spread as it follows: educator 14, psychologists 4 , logopedist (speech therapist) 3 , doctors 5 , physiotherapists 4 , teachers 6 , social workers 4 .

The services delivered in a direct mode after the frequencies are: rehabilitation, psychological support, social integration, help and personal care, training and orientations, information, assessment and diagnose.

Most of these services are provided in the context of: school, social, home, leisure.

$75 \%$ of respondents working in public subject and $25 \%$ in the private subject. Nearly $80 \%$ of them work in a group and $20 \%$ in the individual.

In terms of type of disability with which these professionals have worked more results: mental, multiplicity, speech, motored and finally sensory.

On average the largest percentage of respondents had worked from 5-10 years.

Graph. 1. What do you think is important for a parent at the time of diagnosis communication takes?

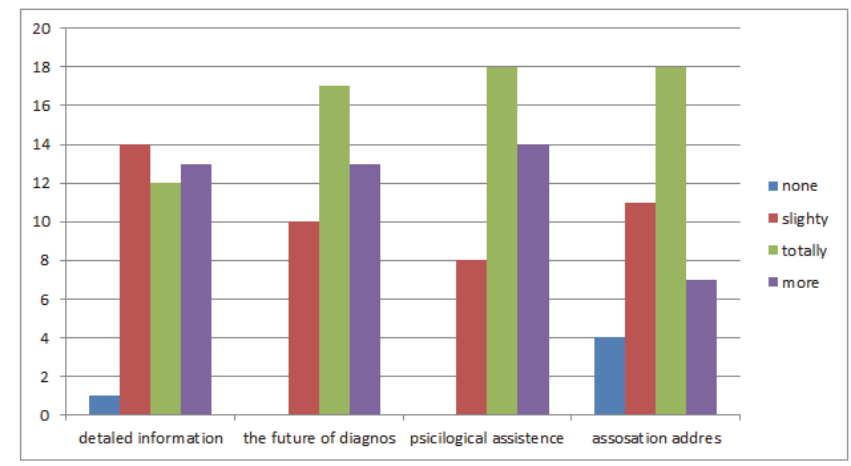

Source: Data elaborated by the author from questionnaire

From the data obtained from the professionals, they noticed that during the time of diagnosis of communication, parents found importance to have a psychological help, information on diagnosis, detail information on the problem and less 
parents seek to address parents' associations.

In a study made by the author on about what it is more important for parents on the communication of the diagnosis, about $45 \%$ of parents state that they find detailed information more important on data after they estimate the performance of diagnosis and then the psychololgical support.

Comparing the viewpoints of professionals and parents about the problem, the first think that they need of psychological support and after, they find the importance of detailed information or the progression of diagnosis. On the other hand, parents prefer to know more on the information and the progress than the help.

From the evidence of professionals, they have observed the engagement of the parents in the problem of their children and that they underestimate on themselves. One professional says: I have been observing a mother through both her births, where in the first the child was healthy and through regular visits on the doctor, the mother was well and she was taking care of herself and her appearance and her activities. After her second birth, where the child was diagnosed with Down Syndrome, mother was asking me about anything that had to do with the child or for the progress of the syndrome but her condition was not the same as it was with her first healthy child, and it was obvious the lack on personal maintance or the withdrawal from different social activities.

In the opinion of some of the professionals asked for this case, what was stated is that parents of children with special needs, have a major need on psychological support but they forget to claim it.

Graph. 2. During the time of the communication of the diagnosis, which are the emotions that parents face of more?

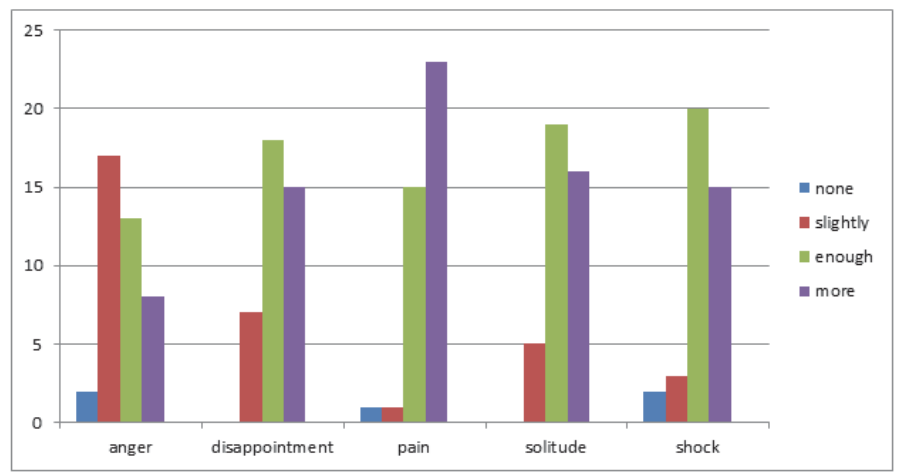

Source: Data elaborated by the author from questionnaire

As it is shown from the graph, the most frequent emotions are pain, loneliness, disappointment, shock and anger. In a study made by the author, parents have stated approximately the same experiences as the professionals did state.

Graph. 3. In your opinion, how much time do parents spent for their children with special needs?

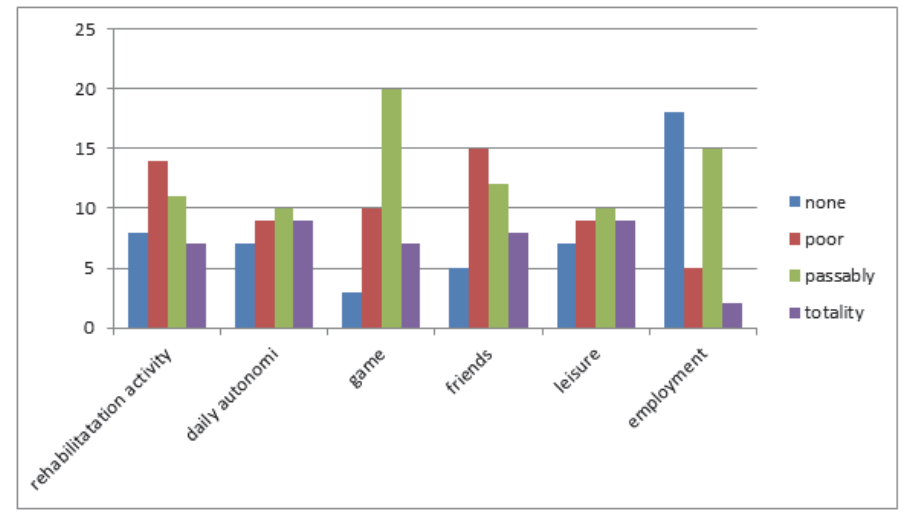

Source: Data elaborated by the author from questionnaire 
From the data it has been concluded that they spent time in play activities. It is noted that the other activities have a different time distribution especially that we have rates close to the time that parents spend enough or not but from these analysis of the questionnaires we noticed that treatment happened in different ages and the majority of the respondents work in institutions where children are handled and not adults. The views that come from the professionals for this question, leave too much for discussion because they are different. However, it is expressed by them that it depends on the age and the children's problems.

In this past we asked which family member spends more time with the children. Most of their time, they spent with their parents and then with the siblings, the rest of the family and less with themselves.

Graph. 4. Who usually takes the decisions that affect the child care?

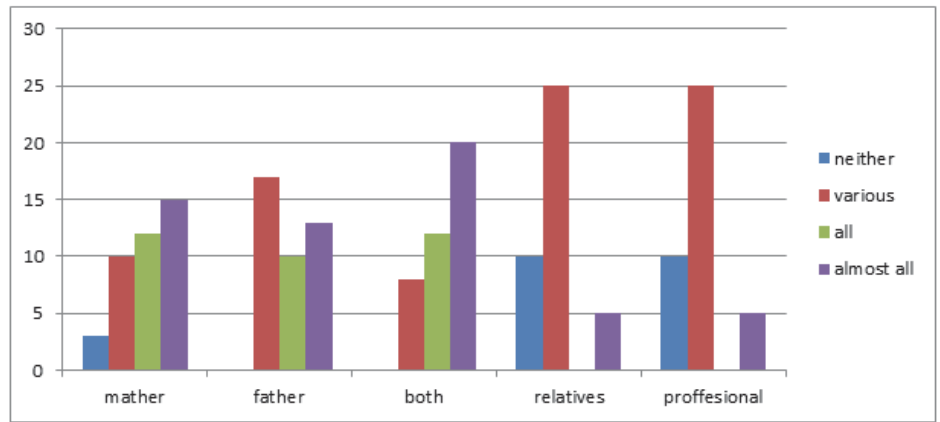

Source: Data elaborated by the author from questionnaire

It seems that the biggest parts of the decisions are taken from both parents ongoing mother, father, family members, professionals.

Professionals claim that they participate in decisions when requested or when parents are not present.

Records taken from a study conducted with the parents' show that they also come to the same conclusion

Graph. 5. What impact do you think that has the child inability for the family in different aspects?

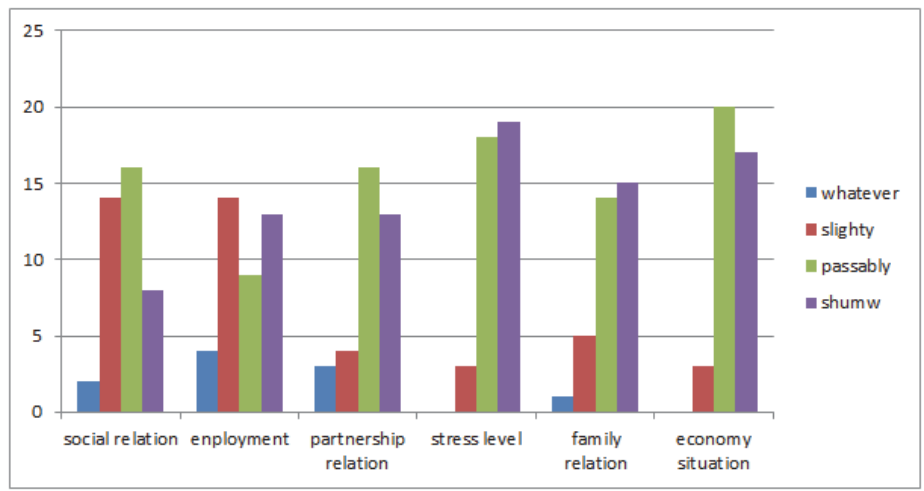

Source: Data elaborated by the author from questionnaire

As perceived by the professionals, the disability of their children affects parental stress levels and continued financial condition, family relationships, marital life, employment and in the end, social life. As seen from professionals, the measurement of such influences depends mostly on the level of disability of their child, the greater the disability, the more family problems in the following components. Professionals are often forced to make the counselor for parents not only for the maintenance of the child but also for their relations in married life. 
Graph. 6. How many parents show these characteristics?

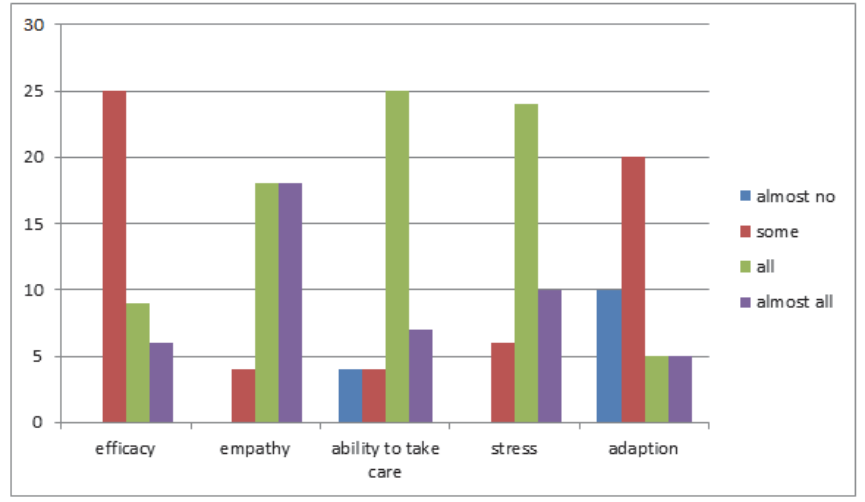

Source: Data elaborated by the author from questionnaire

As it appears the data revealed that parents have more of these characteristics starting from sensitivity, stress, the ability levels of taking care of ourselves stay low efficiency and flexibility. From their comments, high level of stress, exhaustion, which often turns them into a marathon, influences the lack of resilience and efficiency.

How do you judge the self-esteem of parents with children with disabilities compared to others? Between elections sufficiently, inferior, inferior, equal, superior. Professionals at about $70 \%$ stated that families with disable children feel inferior to other families. The rest of, is determined equally with other families.

Graph. 7. What do parents think it is more important for their children with disabilitites?

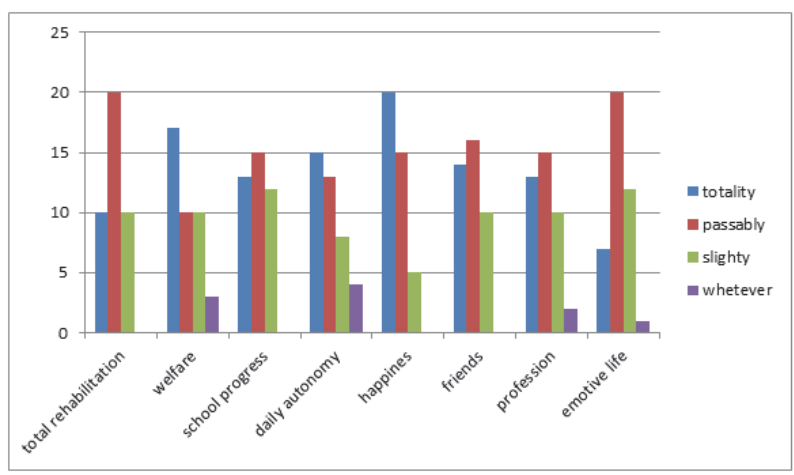

Source: Data elaborated by the author from questionnaire

Results show that what professionals perceive that parents want for their children are being launched by happiness, wellness, everyday autonomy, occupation, school performance, full rehabilitation, emotional life.

Professionals declare that what parents want for their children with special needs is the same as what every other parent would like for their child, only that the amount of claims should be different.

In general terms, what image have you created for these parents?

Among positive, negative and neutral choices, the highest percentage about $80 \%$ said that they have a positive image and $20 \%$ have a neutral one.

In several comments that were expressed, some professionals think that in the construction of their image towards parents depends on their requests as a part of these demands are unreal. One says: their daughter is 15 year old and they (parents) require that she can speak and write, while it was impossible for her to do so. 


\section{Conclusions}

-Professionals over all are concerned to establish a bond of trust and sustainable cooperation with parents and to do everything possible for this to happen. By studying we look at what professionals think about the parents, giving a general review. But what is evident, is it a way to turn into cooperation? The moment after diagnosis and the return to home are facts, decisive moments in their lives, when the report of services but also with other families often question the only way to stand out the moment of psychological difficulty that always follows the birth of a child with disabilities and it is he who opens and closes the road often in acceptance of child jointing.

The doubts parents often take for anxiety insignificant forgetting that parents are the first experts of the child and as such, they deserve to be heard and considered as recipients of trust and not mistrust. A parent that lives 24 hours per day with the child may not have to be professional knowledge but of course they will have the knowledge that daily life forgives from about the flow of "knowing the feeling" that belongs to the family dimension. This intimate and deep and extensive knowledge, if meets appropriate and professional competencies can lead to a collaborative work which makes for both parties to recognize and mutually evaluated. If these two different recognitions of their nature complementary to each other but not accepted, the child actually leaves the issue for the country to leave the half-stereotypical figures, which do not help always in terms on unique and special child.

So all children with disabilities would look "cut" from the same Scissors. It often happens that a parent who wants to say what I know and will share with others, not labeled as active and competent partner in cooperation, but as an antagonist of the problem. Collaboration is a process where knowledge connection both subject that work to recognized and mutually evaluated.

The study revealed that what professionals perceive their parents to identify even what they feel, need, expect, seek, I represent. This recognition makes it even better understand what is and represents family and especially against a child with special needs, which is the common denominator for the practitioner and parent.

\section{Bibliographie}

J.-M. Bouchard, "Modèles éducatifs des mères : origine, cohérence et actualisation", Revue française de pédagogie, 1991, 92, 17-32.

J.-M. Bouchard, "Les relations parents et intervenants : perspectives théoriques", Apprentissage et socialisation, 1996, 17, 1-2.

J.-M. Bouchard, J.-C. Kalubi, G. Chatelanat, I.-M. Panchaud, G. Niggl Domenjoz et P. Beckman, "Partenariat de recherche sur les malaises des professionnels et des parents", Revue francophone de la déficience intellectuelle, 1998, 9(2).

Centre de réadaptation Le Bouclier, Définition du processus de réadaptation et des services au CR Le Bouclier, Saint-Jérôme, CR Le Bouclier, 2004

Centre de réadaptation Le Bouclier, Document de référence pour l'élaboration des plans d'intervention individualisés (PII) au CR Le Bouclier, Saint-Jérôme, CR Le Bouclier, 2004.

C. J. Dunst, M. D. Trivette et A. G. Deal, Enabling and Empowering Families: Principles and Guidelines for Practice, Cambridge, MA, Brookline Books, 1988.

J.-C. Kalubi et J.-M. Bouchard, "Difficultés de communication dans les relations entre familles et professionnels", Éducation et francophonie, 2003, XXXI(1).

C. R. Rogers, On Becoming a Person. A Therapist's View of Psychotherapy, Boston, Houghton Mifflin, 1961.

D.-A. Schön, Le praticien réflexif. À la recherche du savoir caché dans l'agir professionnel,Montréal, Logiques, 1994. 